Article

\title{
Forecasting of Electrical Generation Using Prophet and Multiple Seasonality of Holt-Winters Models: A Case Study of Kuwait
}

\author{
Abdulla I. Almazrouee ${ }^{1, *(\mathbb{D})}$, Abdullah M. Almeshal $\left.{ }^{2} \mathbb{(}\right)$, Abdulrahman S. Almutairi ${ }^{3}$, \\ Mohammad R. Alenezi ${ }^{2}$ D, Saleh N. Alhajeri ${ }^{1}$ and Faisal M. Alshammari ${ }^{4}$ \\ 1 Department of Manufacturing Engineering Technology, College of Technological Studies, P.A.A.E.T., \\ P.O. Box 42325, Shuwaikh 70654, Kuwait; sn.alhajeri@paaet.edu.kw \\ 2 Department of Electronics Engineering Technology, College of Technological Studies, P.A.A.E.T., \\ P.O. Box 42325, Shuwaikh 70654, Kuwait; am.almeshal@paaet.edu.kw (A.M.A.); \\ mr.alenezi@paaet.edu.kw (M.R.A.) \\ 3 Department of Mechanical Power and Refrigeration Technology, College of Technological Studies, P.A.A.E.T., \\ P.O. Box 42325, Shuwaikh 70654, Kuwait; asa.almutairi@paaet.edu.kw \\ 4 Engineering and Environmental Department, Ministry of Electricity and Water, \\ Ministries Zone 12010, Kuwait; fmnalshammari@mew.gov.kw \\ * Correspondence: ai.almazrouee@paaet.edu.kw
}

Received: 31 October 2020; Accepted: 23 November 2020; Published: 26 November 2020

\begin{abstract}
Electrical generation forecasting is essential for management and policymakers due to the crucial data provided for resource planning. This research employs the Prophet model with single and multiple regressors to forecast the electricity generation in Kuwait from 2020 to 2030. In addition, multiple seasonality Holt-Winters models were utilized as a benchmark for comparative analysis. The accuracy, generalization, and robustness of the models were assessed based on different statistical performance metrics. The triple seasonality Holt-Winters model achieved superior performance compared with the other models with $\mathrm{R}^{2}=0.9899$ and MAPE $=1.76 \%$, followed by the double seasonality Holt-Winters model with $\mathrm{R}^{2}=0.9893$ and MAPE $=1.83 \%$. Moreover, the Prophet model with multiple regressors was the third-best performing model with $\mathrm{R}^{2}=0.9743$ and $\mathrm{MAPE}=2.77 \%$. The forecasted annual generation in the year 2030 resulted in 92,535,555 $\mathrm{kWh}$ according to the best performing model. The study provides an outlook on the medium- and long-term electrical generation. Furthermore, the impact of fuel cost is investigated based on the five forecasting models to provide an insight for Kuwait's policymakers.
\end{abstract}

Keywords: prophet model; multiple seasonality; Holt-Winters model; long-term forecasting

\section{Introduction}

Accurate electrical generation forecasting is essential for the management and policymakers of local and national power plants. Electric power generation is one of the complex processes where many parameters are involved and need to be optimized to deliver the electricity continuously and efficiently to the whole population [1]. On the other hand, power generation is faced with many challenges, such as environmental legislation, fluctuations in fuel prices, and the need to optimize the available resources. Moreover, different sources for power generation are used nowadays. These sources include nuclear energy, fossil fuel such as coal, natural gas, crude oil, other gasses, and renewable energy such as hydropower, solar, wind, municipal solid waste, and geothermal. Therefore, appropriate forecasting is a need for these power plants in order to support continued prosperity. 
Forecasting horizons vary from short-term to mid-term and long-term horizons [2-6]. Long-term forecasting is the most complex and critical due to the different parameters involved [6,7]. Parameters include population, gross domestic product (GDP), consumer behavior, the advancement of technology, and weather temperature. Long-term forecasting is facilitated to predict the future maximum peak loads and/or annual demand and generation [3]. The forecast of maximum peak loads helps make significant decisions such as constructing new power plants and/or any expansion. On the other hand, forecasting the annual electrical generation provides critical data to define future power needs and assess logistics, such as fuel and personnel needed for the specified generation. Accurate forecasting guarantees efficient resource planning for the growing population and increasing demand for electricity that avoids over or underestimating the procurement of resources such as fuel.

Different kinds of approaches are employed for electrical load demand forecasting in the literature with several parameters in various complexity degrees to attain the best electricity demand forecasting accuracy. The methods can be categorized into two main categories: conventional models and artificial intelligence (AI) models [2-6]. Conventional methods include time series models, exponential smoothing, regression models, and gray models $[2,3,8]$. In contrast, artificial intelligence models include models such as machine learning (ML) models, deep learning (DL) models, genetic algorithm (GA) models, artificial neural networks (ANN) based models, and support vector regression (SVR) $[2,3,8]$.

Various studies investigated the long-term forecasting of electricity demand from different angles using multiples approaches. Perez-Garcia and Moral-Carcedo [9] developed long-term forecasting for electricity demand in Spain until 2030, based on a simple growth decomposition scheme to identify other key factors. Torrini et al. [10] used a fuzzy logic approach to forecast Brazil's long-term annual electricity demand and extract rules from the input variables. Pessanha and Leon [11] decomposed the total electricity residential consumption in Brazil into three variables: the number of households, the average consumption of customers, and the electrification rate, and found the forecast by the product of the forecast of the three variables. Mohamed and Bodger [12] used multiple linear regression analyses to investigate the electricity consumption correlation of GDP, population, and the average price of electricity during the period 1965-1999 of New Zealand. Ardakani and Ardehali [13] developed an artificial neural network (ANN) and optimized regression models with improved particle swarm optimization (IPSO) to forecast electrical energy consumption of Iran and the U.S. for 2010-2030. Bianco et al. [14] presented different regression models based on co-integrated or static data using historical data from 1970 to 2007 to develop a long-term consumption forecasting model for Italy. Chen and Wang [15] implemented a collaborative principal component analysis and fuzzy feed-forward neural network (PCA-FFNN) methodology in addition to the partial-consensus fuzzy intersection and radial basis function network (PCFI-RBF) approach to forecast the electrical loads of Taiwan. Silva et al. [16] presented a methodology that associates hierarchical models with the bottom-up approach and the inclusion of the Bayesian inference to develop forecasting of electricity consumption for the pulp and paper industry in Brazil ranging from 2015 until 2050.

A relatively new methodology is introduced by researchers from Facebook called Prophet model [17]. It is a simple yet robust for estimation because of its structure of adjusting parameters without investigating the original model's details. It contains a decomposable time series model with three main model components: trend, holidays, and seasonality. In a recent study [18], the Prophet model outperformed the well-established Holt-Winters model in Kuwait's long-term peak load forecasting. The use of this method in forecasting is expected to spread due to its robustness and accuracy. On the other hand, recent advances are employed on the Holt-Winters model [19], which probably improves its accuracy. A recent study by Jiang et al. [20] predicted the electricity consumption of a city in China by proposing a hybrid forecasting model and using the fruit fly optimization algorithm to select the optimum smoothing parameters.

One of this study's main contributions is to explore the use of the Prophet forecasting model, with single and multi-regressors, and the multi-seasonality Holt-Winters model for the long-term 
forecasting of electricity generation. The dataset is based on the State of Kuwait as a case study with a historical dataset from January 2015 to May 2020.

Kuwait is a country in the Middle East, and its economy is dependent on oil. The major commodities in Kuwait, such as electricity, are supported financially and owned by the government, aiming to keep them as low as possible for customers. Kuwait has eight conventional power plants located in different cities with a total installed 19,673 megawatts [21]. Electricity peak demand in Kuwait varied dramatically in the last 70 years with a generally decreasing trend. The average annual increase in the fifties was around $32 \%$, then it decreased to $26 \%$ in the sixties to $15 \%$ in the seventies and reached around $8 \%$ in the nineties. The annual increase rate has decreased during the last twenty years and reached around 3.68\% in 2019 [22-24]. There is a dramatic increase in the population and consumption per capita, as depicted in Table 1 below. The increase in electricity generation is attributed to population growth and economic development [25]. The annual energy use per capita in 2018 is $14,235 \mathrm{kWh}$, which is considered very high and among the world's highest. [21-24,26]. The average household in Kuwait consumed is reported [27] in 2014 to be about 38 MWh, which is the highest globally. The severe hot weather in summer and historically low prices are considered the main reasons for this increase. However, other factors, such as people's lifestyles, inefficient construction practices, and installed equipment, might also contribute [26].

Table 1. The growing population and per capita consumption in three decades [21].

\begin{tabular}{cccc}
\hline Year & Population & $\begin{array}{c}\text { Per Capita Consumption } \\
\text { kWh/Person }\end{array}$ & $\begin{array}{c}\text { Mean Annual Rate of } \\
\text { Growth during 10 Years \% }\end{array}$ \\
\hline 1989 & $2,048,000$ & 10,295 & - \\
1999 & $2,148,032$ & 12,552 & $3.87 \%$ \\
2009 & $3,484,881$ & 13,372 & $0.65 \%$ \\
2019 & $4,776,407$ & 14,002 & $0.51 \%$ \\
\hline
\end{tabular}

One of the main points proposed [28] for fixing the high generation's need is to tackle the subsidized energy prices, which inspire greater electricity. Another viable idea is the use of dynamic pricing [29], which can change the pattern or reduce the quantity of people's electricity consumption. Increasing electricity tariffs is expected to be a significant contributor to change the consumption pattern of people. However, there are some difficulties in implementing these reforms due to their political nature [28]. Alajmi [30] used energy audit techniques and implemented non-retrofitting and retrofitting on a two-story educational facility that results in more than $50 \%$ annual total saving for governmental buildings. The Ministry of electrical and water, especially with the need to mitigate climate change, aims to reach a generation of $15 \%$ of renewable energy by 2035 [31]. Moreover, the government is encouraging people to use renewable energy and new technology, which might lead to decentralize the power systems and might also reduce the effect on government [22]. The introduction of new sustainable buildings and cities that implement renewable energy and efficiently use the electricity, especially with new residential cites in Kuwait, is feasible and efficient [22]. Digitalization through the use of smart meters and smart grid is also believed to provide more reduction and sustainable use of the electricity and are discussed by the Ministry of electrical and water and should come into action [22]. However, remedies for the increase in the generation and their consequences are out of this study's scope.

The continuous increase in electricity generation and the different plans of government necessitate carrying out more studies in forecasting. Studies are needed to estimate the total electricity generation for the coming years to assist the policymakers in achieving the proper decisions regarding the future. Several studies were carried out regarding long-term forecasting for Kuwait. However, most of them were about peak load forecasting [18,32-37]. Alajmi and Phelan [32] used a bottom-up approach to create a baseline for the residential sector's end-use energy profile in Kuwait until 2040. Recently, Alhajeri et al. [35] investigate the effects of COVID-19 on electrical consumption from 1st March to 30th 
May. Atalla and Hunt [37] studied high residential electricity demand drivers in the Gulf Cooperation Council countries (GCC) using the time series model and suggested some recommendations to reduce the demand.

To the best of authors' knowledge, limited studies have investigated the Prophet model's use in forecasting the electricity generation. The originality of this study is that it explores the performance of prophet model with multi-regressors in long-term forecasting of electricity generation. The multi-regressors are the historical daily maximum and minimum load, temperature and population. In addition, comparative quantitative analyses with multi-seasonality Holt-Winters model is presented to assess the forecasting performance. Furthermore, the generalizability and robustness of the Prophet and Holt-Winters methods for forecasting long-term electricity generation are explored and presented. Various factors of the future are changing, such as population, weather temperatures, and peak loads, directly or indirectly related to electricity generation were taken into account in the forecasting. The study also provides and discusses the estimation of the expected future fuel consumption cost until 2030.

The paper is structured as follows. Section 2 presents a description of the Prophet and the multi-seasonality Holt-Winter models. Section 3 illustrates the results and analyses based on the performance indicators. In addition, Section 3 provides insight for policymakers on the implications of electrical generation on fuel costs.

\section{Methodologies}

The electrical generation's real data between January 2015 and July 2020 was attained from the Ministry of Electricity and Water (MEW) is used in this research. The data is plotted in Figure 1, showing the daily generation for approximately six years. A vivid seasonality of the data is observed with an annual maximum generation in the hot summer, especially June to August. There is an increasing trend of the generation, as noticed from Figure 1, due to the growth of population, the building of new cities, as well as economic development, and this is expected to continue in the upcoming years.

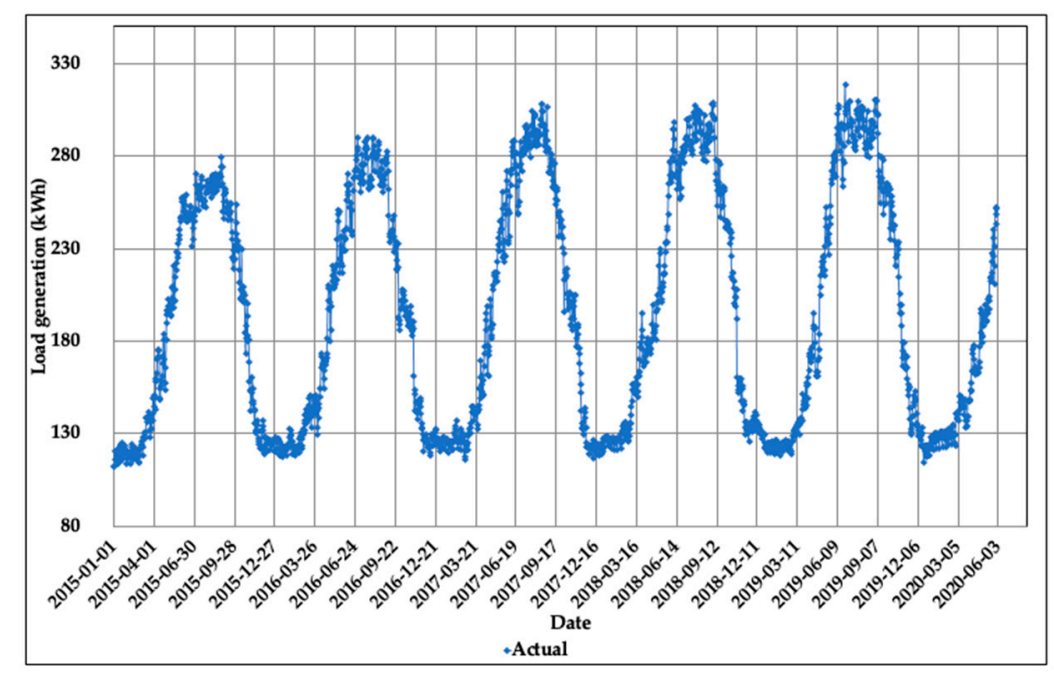

Figure 1. The actual data of generated daily loads data in Kuwait between January 2015-May 2020.

The data consists of five years with daily observations for electrical generation from January 2015 to May 2020 with 1978 data points. Taking a closer look at Figure 1, a yearly seasonality occurring within July-August, can be observed. During these months, the high electricity demand is due to Kuwait's hot summer, with temperatures reaching $55^{\circ} \mathrm{C}$. The data also reveals a weekly seasonality with low demand on Fridays and Saturdays each week due to the factories' and industries' closure on weekends. Furthermore, the third seasonality corresponds to the year's meteorological seasons and will be addressed hereafter as quarters to avoid the confusion with methods' seasonality patterns. 
In this study, long-term forecasting for electrical generation for the coming ten years is aimed. Therefore, a search for models that comprise data with time-series nature with different seasonality resulted in choosing the relatively new Prophet model from Facebook and the Holt-Winters model for this work.

The relatively new Prophet model possesses some features such as tunable parameters by an expert during the analysis, which allows for fine-tuning and the ability to reach robust forecasting. The model's automatic tuning does not require a full understanding of the underlying model, making it easier to use. Limited studies are reported to use this model and proved to achieve vigorous results [18,38]. Whereas the Holt-Winters model, with different variations, is used extensively for long-term forecasting and providing excellent results $[39,40]$.

One of the Prophet model's points of superiority is its ability to deal with missing data and reach outstanding results. The Prophet model's flexibility for complex data can be achieved using an analyst-in-the-loop feature by integrating multiple-seasonality of different periods. The availability of single and multivariate forecasting in a straightforward manner adds a new strength for the Prophet model. On the other hand, Holt-Winters deals only with univariate forecasting. There exist different Holt-Winters model variations in the literature where it was generalized to include double and triple seasonalities [41,42]. The Holt-Winter model was then generalized and introduced in literature to include n-seasonalities and was therefore known as nHWT [38]. Initialization methods of nHWT were proven to have a crucial impact on the accuracy of the forecast [19].

In this research, the multivariate Prophet forecasting model is utilized to forecast the annual load generation needed in Kuwait for the upcoming 10 years and is compared with the univariate nHWT forecasting model with initialization methods. In the next sections, the implementation of the various Prophet and Holt-Winters forecasting methods is presented in detail.

\subsection{Prophet Forecasting Method}

A Prophet model is used with simple or complicated time-series data that includes single or multiple seasonality, holidays, and data trends. Multiple seasonality can include different patterns, such as days, weeks, months, and years. As reported by Taylor and Letham [17], the mathematical representation of the decomposed time series model:

$$
y(t)=g(t)+s(t)+h(t)+\varepsilon_{t}
$$

where $g(t)$ denotes the data trend function, $s(t)$ denotes the seasonality, and $h(t)$ denotes holidays effect that can be added within specific points of the data and as an extra regressor. The error term, $\varepsilon_{t}$, denotes any distinctive features of the data that are not fitted by the model.

Prophet trend function, $g(t)$, can be signified by a piecewise linear growth model or a saturating growth model. Since the electrical generation does not exhibit a saturating growth, a piecewise linear growth model is utilized as:

$$
g(t)=\left(k+a(t)^{T} \delta\right) t+\left(m+a(t)^{T} \gamma\right)
$$

where $k$ represents the growth rate, $\delta$ represents adjustment rate, $m$ represents the offset parameter, and $\gamma$ is the trend changepoints, $s_{j}$, and is set as $-s_{j} \delta_{j}$, with $a(t)$ defined as:

$$
a_{j}(t)=\left\{\begin{array}{cc}
1 & \text { if } t \geq s_{j} \\
0 & \text { otherwise }
\end{array}\right.
$$

The change points allow the analyst in the loop to adjust the resulting forecast based on a previous experience. Therefore, the trend of the forecast can be hence fine-tuned and results in an enhanced forecast. The seasonality function $s(t)$ can be modelled by Fourier series to represent daily, weekly, 
and yearly seasonality as well as to incorporate more complex seasonality patterns by higher order Fourier series. The seasonality function is hence written as:

$$
s(t)=\sum_{n=1}^{N}\left(a_{n} \cos \left(\frac{2 \pi n t}{P}\right)+b_{n} \sin \left(\frac{2 \pi n t}{P}\right)\right)
$$

where $P$ is assumed to be 365.25 for yearly seasonality pattern. Furthermore, Prophet model allows adding extra regressors to enhance the forecast results. The holiday effects, as example, can be incorporated using $h(t)$ function and define a list of holiday dates as a matrix of regressors $Z(t)$ defined as:

$$
\begin{gathered}
Z(t)=\left[1\left(\mathrm{t} \in D_{1}\right), \ldots, 1\left(\mathrm{t} \in D_{\mathrm{L}}\right)\right] \\
h(t)=Z(t) \kappa
\end{gathered}
$$

with $D$ as the set of holiday dates, $\kappa \sim \operatorname{Normal}\left(0, v^{2}\right)$ with $v$ as the holiday smoothing parameter. In this work, additional regressors were utilized and defined as the temperature, the maximum load, the minimum load, and the population to result in a more reliable forecast that reflects the growth in population and Kuwait's average temperatures.

\subsection{Holt-Winters Forecasting Model}

Holt-Winters models are well-established models that have two seasonal variations: additive and multiplicative types. The additive method is appropriate for fitting a time series data with a constant seasonal variation. Whereas multiplicative method is appropriate for a time series with an increasing seasonal pattern relative to the data level. The generalized Holt-Winters model was reported in literature $[19,41,43]$. In this research, the generalized Holt-Winters model with multiple seasonality and initialization methods is used for forecasting the electrical generation of Kuwait until 2030.

The Holt-Winters model consists of forecast equation and smoothing equations of the level, trend, and seasonality of the time series. Assuming that $S_{t}$ represents the seasonality, $T_{t}$ to represent the trend and that $I_{t}$ corresponds seasonality, the additive trend multiplicative seasonality HW model can be defined as:

$$
\begin{gathered}
S_{t}=\alpha\left(\frac{X_{t}}{\prod I_{t-s_{i}}^{i}}\right)+(1-\alpha)\left(S_{t-1}+T_{t-1}\right) \\
T_{t}=\gamma\left(S_{t}-S_{t-1}\right)+(1-\gamma) T_{t-1} \\
I_{t}^{i}=\delta^{i}\left(\frac{X_{t}}{S_{t} \prod_{j \neq 1} I_{t-s_{j}}^{i}}\right)+\left(1-\delta^{i}\right) I_{t-s_{i}}^{i} \\
\hat{X}_{t}(k)=\left(S_{t}+k T_{t}\right) \prod_{i} I_{t-s_{i+k}}^{i}+\varphi_{A R}^{k}\left(X_{t}-\left(S_{t-1}+k T_{t-1}\right) \prod_{i} I_{t-s_{i}}^{i}\right)
\end{gathered}
$$

where $S_{t}$ represents the level, $T_{t}$ as the trend, $I_{t}^{i}$ to correspond to multiple seasonality and $\hat{X}_{t}(k)$ is the $\mathrm{k}$-step ahead forecast. The smoothing parameters are defined as $\alpha$ for the level smoothing, $\gamma$ as the trend smoothing parameter, and $\delta^{i}$ as the smoothing parameters of each seasonal pattern with cycle length of $S_{i}$. The term $\varphi_{A R}^{k}$ is an adjustment for the first autocorrelation error.

There exist various initialization methods for the level, trend, and seasonality in order to enhance the forecast accuracy [19]. The trend is initialized as $T_{0}=0$ for an additive trend. Whereas the level equation is initialized by the moving average value of the dataset and is obtained by:

$$
S_{0}=\frac{1}{S_{m}}\left[\frac{X_{1+s_{m}}-X_{1}}{s_{m}}+\frac{X_{2+s_{m}}-X_{2}}{s_{m}}+\cdots+\frac{X_{2 s_{m}}-X_{s_{m}}}{s_{m}}\right]
$$


The seasonality is initialized by the method presented by Brockwell and Davis [39] and adopted by the National Institute of Standards (NIST) which depends on calculating the weights of the data series against the multiple seasonality pattern values. The proposed method is presented in the following steps:

Step 1: Compute the yearly average as $A_{m}^{i}$ for each seasonality of length $s_{m}$ and has a pattern of $n_{q}$ times in the dataset

$$
A_{m}^{i}=\frac{\sum_{j=1}^{s_{i}} X_{(m-1) s_{i}+j}}{s_{i}} \text { for } m=1,2, \ldots, n_{q}
$$

Step 2: Divide the observations by the yearly averages as:

\begin{tabular}{ccccc}
\hline index & $\mathbf{1}$ & $\mathbf{2}$ & $\ldots$ & $\mathbf{q}$ \\
\hline 1 & $\frac{X_{1}}{A_{1}^{i}}$ & $\frac{X_{s_{i}+1}}{A_{2}^{i}}$ & $\ldots$ & $\frac{X_{s_{i}+1}}{A_{q}^{i}}$ \\
$\ldots$ & $\ldots$ & $\ldots$ & $\ldots$ & $\ldots$ \\
$s_{i}$ & $\frac{X_{s_{i} 1}}{A_{1}^{i}}$ & $\frac{X_{2 s_{i}}}{A_{2}^{i}}$ & $\ldots$ & $\frac{X_{m_{1} s_{i}+1}}{A_{m_{i}}}$ \\
\hline
\end{tabular}

Step 3: Write each seasonality as:

$$
\begin{gathered}
I_{1-s_{i}}^{*(i)}=\frac{\frac{X_{1}}{A_{1}^{i}}+\frac{X_{s_{i}+1}}{A_{2}^{i}}+\cdots+\frac{X_{\left(m_{i}-1\right) s_{i}+1}}{A_{m_{i}}^{i}}}{m_{i}} \\
I_{1-s_{i}}^{*(i)}=\frac{\frac{X_{1}}{A_{1}^{i}}+\frac{X_{s_{i}+1}}{A_{2}^{i}}+\cdots+\frac{X_{m_{i} s_{i}+1}}{A_{m_{i}}^{i}}}{m_{i}}
\end{gathered}
$$

Step 4: Write the seasonal indices as:

$$
I_{1-s_{i}}^{*(i)}=\left\{\begin{array}{c}
I_{t-s_{1}}^{*(i)} i=1, t=1, \ldots, s_{i} \\
\frac{I_{t-s_{1}}^{*(i)}}{\prod_{j=1}^{i-1} I_{t-s_{j}}^{(i)}} i>1, t=1, \ldots, s_{i}
\end{array}\right.
$$

The simulation parameters are presented in Table 2 with the values of level, trend and seasonality smoothing parameters as $\alpha, \gamma, \delta^{i}$ respectively. The seasonality smoothing parameters are presented as $\delta^{y}, \delta^{q}$ and $\delta^{w}$ that corresponds to the yearly, quarterly, and weekly seasonality smoothing parameter values.

Table 2. Multi-seasonality Holt-Winter parameters.

\begin{tabular}{cccc}
\hline Method and Seasonality & $\alpha$ & $\gamma$ & $\delta^{i}$ \\
\hline HWSS-yearly & 0.048 & 0.023 & $\delta^{y}=0.3$ \\
\hline HWDS_weekly, yearly & 0.039 & 0.029 & $\begin{array}{l}\delta^{y}=0.32 \\
\delta^{w}=0.28\end{array}$ \\
\hline HWTS-daily, weekly, yearly & 0.042 & 0.025 & $\begin{array}{l}\delta^{y}=0.3 \\
\delta^{q}=0.29 \\
\end{array}$ \\
\hline
\end{tabular}

\subsection{Performance Indicators}

In order to evaluate the performance of each model in terms of accuracy, various statistical metrics were adopted, such as root mean square error (RMSE), the mean absolute percentage error (MAPE), coefficient of determination $\left(\mathrm{R}^{2}\right)$, mean absolute error (MAE), and coefficient of variation of root mean square error (CVRMSE) that can be expressed as in the following equations: 


$$
\begin{gathered}
\text { RMSE }=\frac{\sqrt{\sum_{i=1}^{n}\left(\hat{y}_{i}-y_{i}\right)^{2}}}{n} \\
\text { CVRMSE }=\frac{\sqrt{\sum_{i=1}^{n}\left(\hat{y}_{i}-y_{i}\right)^{2}}}{\breve{y}} \\
\text { MAE }=\frac{1}{n} \sum_{i=1}^{n}\left|y_{i}-\hat{y}_{i}\right| \\
\text { MAPE }=\frac{1}{n} \sum_{i=1}^{n}\left|\frac{\hat{y}_{i}-y_{i} \mid}{y_{i}}\right| \times 100 \% \\
R^{2}=1-\frac{\sum_{i=1}^{n}\left(y_{i}-\hat{y}_{i}\right)^{2}}{\sum_{i=1}^{n}\left(y_{i}-\breve{y}\right)^{2}}
\end{gathered}
$$

where $y, \hat{y}$, and $\breve{y}$ represent the measured, predicted, and averaged values respectively.

\section{Results and Discussion}

Different models are employed to forecast the electrical generation for Kuwait up to 2030 using real data from the Kuwait Ministry of electrical and water. The simulations were carried out within Rstudio and Matlab software environments. The period between January 2015 to December 2018 was used for estimation and adjustment, while the period from January 2019-May 2020 was used for the validation, and the forecasting horizon is between June 2020 to December 2030.

Single (PSR) and multiple (PMR) regressors were used for Prophet model, and three methods of seasonality Holt-Winters models: single (HWSS), double (HWDS), and triple (HWTS). Each model's performance is assessed from different angles by accuracy indicators. The future electrical generation forecasting of Kuwait until the year 2030 using the five models is plotted in Figure 2a,b. The models are assessed in the following section and then discussed, and different fuel cost scenarios are investigated.

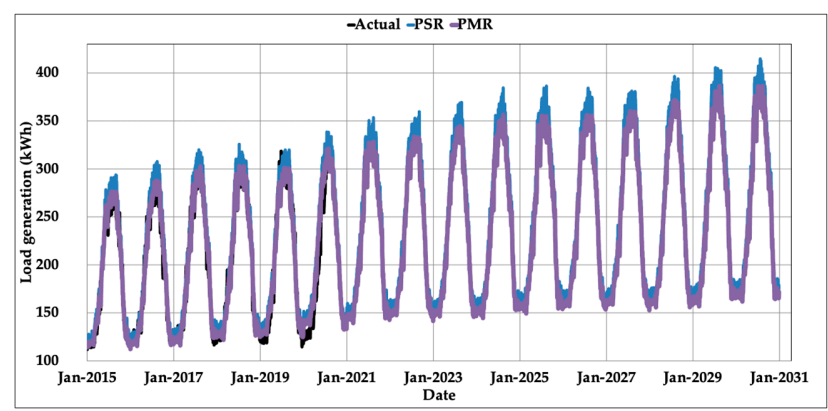

(a)

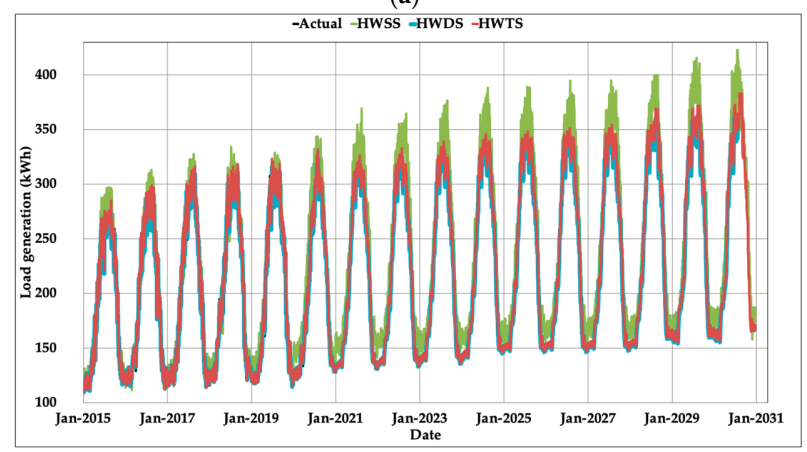

(b)

Figure 2. The generation of daily loads data in Kuwait: the trained, predicted, and forecasted data using the five models of (a) two types of the Prophet model and (b) three types of the Holt-Winters model. 


\subsection{Model Assessments}

Several performance indicators were employed to investigate the reliability of the forecasting of the used models. These indicators are discussed in this section to assess the accuracy and generalization of the used models. Five accuracy performance statistical metrics were employed in this study. These metrics include MAPE, MAE, RMSE, CVRMSE, and $\mathrm{R}^{2}$. Each of the metrics shed light on one angle of the accuracy of the data. MAPE can be considered one of the utmost used tools for evaluating the accuracy of models. MAE reveals the difference between the estimated value and the real value using the absolute error. RMSE assesses the variability of model response regarding variance and sensitivity to large errors. CVRMSE standardizes the forecasted error and provides a unit-less metric that evaluates the variability of the errors between predicted and real values.

Table 3 presents the calculated values of various statistical performance metrics (MAPE, MAE, RMSE, CVRMSE, and $\mathrm{R}^{2}$ ) for the used models. Five different models were used: The single Prophet, multiple Prophet models, single, double, and triple seasonality Holt-Winters models. Abbreviations are used to denote the different models used: PSR denotes a Prophet single regressor model. PMR denotes Prophet multiple regressors model, HWSS denotes Holt-Winters with single seasonality model, HWDS denotes Holt-Winters with double seasonality model, and HWTS denotes Holt-Winters with triple seasonality model. The triple seasonality Holt-Winters model achieved a superior value of accuracy in comparison with other model's performance metrics. The double seasonality Holt-Winters model was the second with all performance measures comparable to the triple seasonality model. MAPE was proposed as a reference indicator for assessing energy forecasting performance at different horizons [2]. All models achieved a low MAPE value of less than 5\%, which indicates the models' high accuracy. It is benchmarked [40] that When MAPE is less than $10 \%$, it is considered a highly accurate model. Highly accurate models were then categorized into four levels, with the best model denoted by I level when MAPE is $\leq 1.2 \%$. Other levels are as follows: II (1.2-2.8\%), III (2.8-4.6\%), and IV (4.6-10\%) [2]. Three of the used models, namely the multiple Prophet model and the double and triple seasonality of Holt-Winters models, fall in the II level of this rating, whereas the other two, namely single Prophet and single seasonality of Holt-Winters model, fall in the III level. The triple seasonality Holt-Winters model outperforms all the other models in MAPE value. Superiority is also observed for both double and triple seasonality Holt-Winters models in MAPE values compared to other models. The MAPE values were $1.76 \%$ and $1.83 \%$ for triple and double seasonality Holt-Winters models, respectively.

Table 3. The calculated values of different performance statistical metrics for the used models.

\begin{tabular}{cccccc}
\hline Indicator & PSR & PMR & HWSS & HWDS & HWTS \\
\hline MAPE & $3.18 \%$ & $2.77 \%$ & $3.29 \%$ & $1.83 \%$ & $1.76 \%$ \\
MAE & 120.10 & 78.23 & 127.82 & 54.01 & 46.82 \\
RMSE & 153.81 & 104.38 & 165.08 & 75.09 & 67.05 \\
CVRMSE & 22.92 & 16.26 & 24.50 & 11.22 & 10.45 \\
R $^{2}$ & 0.9709 & 0.9743 & 0.9641 & 0.9893 & 0.9899 \\
\hline
\end{tabular}

The coefficients of determination, $\mathrm{R}^{2}$, of the five models are plotted with excellent values in Figure 3, showing small differences among the forecasted and real data values. The best-fitting was for the Holt-Winters model's triple seasonality with $\mathrm{R}^{2}=0.9899$, then to the Holt-Winters model's double seasonality $\mathrm{R}^{2}=0.9893$ followed by multiple Prophet model with $\mathrm{R}^{2}=0.9743$. The least values of $\mathrm{R}^{2}$ were 0.9709 and 0.9641 for the single Prophet model and single seasonality of the Holt-Winters model, respectively. The MAE of the best model, which is the triple seasonality of Holt-Winters, was found to be 47.82, whereas the value of MAE for the least model, which was the single seasonality Holt-Winters model, was 127.82 , which is approximately three times of the triple model. 


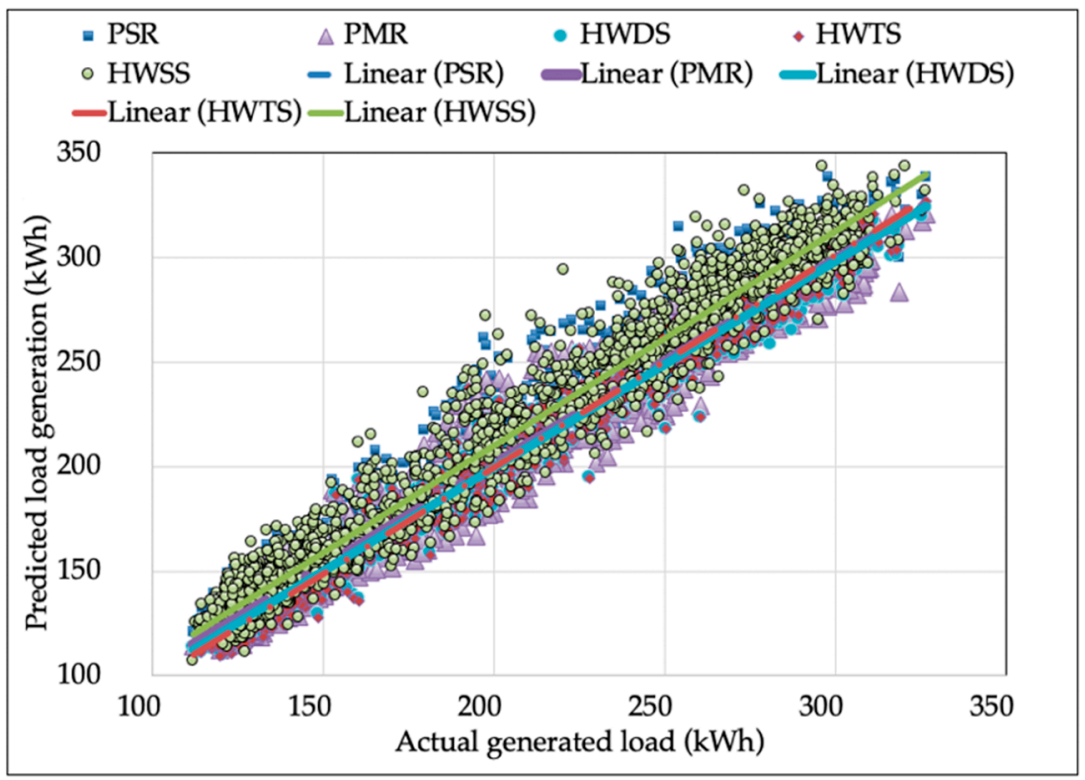

Figure 3. The coefficient of determination $R^{2}$ and the fitting characteristics of real and simulated data for all the models.

The RMSE value of the Holt-Winters model's triple seasonality was also the lowest with a value of 67.05 among the other models, followed by the double seasonality with a value of 75.09 , whereas the single seasonality of the Holt-Winters model was the maximum with a value of 165.06. Similarly, the CVRMSE percentage of the Holt-Winters model's triple seasonality was the least compared to other models, followed by the double seasonality. Therefore, based on the statistical performance metrics, it is vividly clear that the triple seasonality of the Holt-Winters model has a superior fitting and better accuracy compared to other used models followed by the double seasonality of the Holt-Winters model.

A model's generalization is measured by a model's capability to estimate samples beyond the training zone. The five models' relative error variations are shown in Figure 4 with a maximum relative error value of less than $40 \%$ for all models. The triple seasonality of the Holt-Winters model values was less than $21 \%$, and the maximum was for the single seasonality of the Holt-Winters model. The worst relative error was for the single seasonality of the Holt-Winters model.

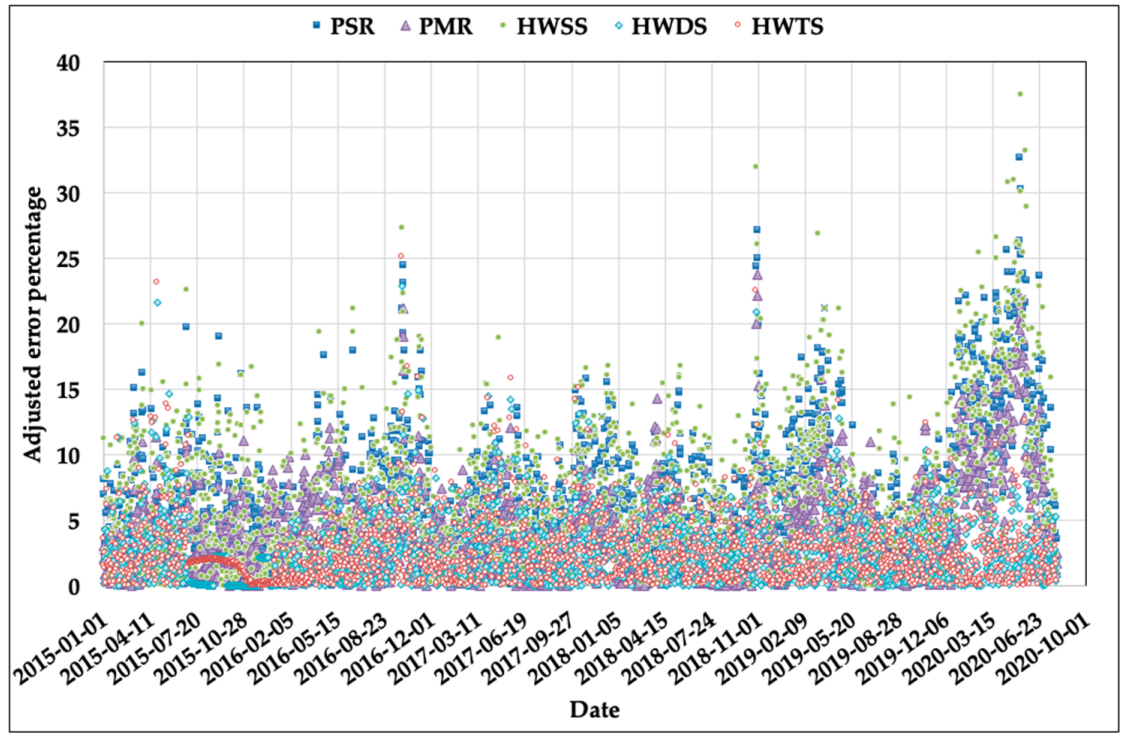

Figure 4. Relative errors percentage for the five models. 
The models' robustness is assessed by incorporating different Gaussian white noise intensities into the real tested data similar to relevant previous studies [44-46]. The data were divided into a training dataset and several testing sets with each set corresponding to a different noisy intensity. Four different intensities of $20 \%, 40 \%, 60 \%$, and $80 \%$ were utilized to investigate the robustness of the five models. The models' robustness was evaluated through the accuracy of the coefficient of determination $\mathrm{R}^{2}$ by studying the random distributed Gaussian white noise on the training dataset. Table 4 shows the variance of $R^{2}$ affected by different noise intensities.

Table 4. The accuracy reduction in coefficient of determination for different models under various noise intensities.

\begin{tabular}{cccccc}
\hline Noise Intensity & PSR & PMR & HWSS & HWDS & HWTS \\
\hline $0 \%$ & 0.9709 & 0.9743 & 0.9641 & 0.9893 & 0.9899 \\
$20 \%$ & 0.9697 & 0.9710 & 0.9619 & 0.9853 & 0.9872 \\
$40 \%$ & 0.9671 & 0.9705 & 0.9592 & 0.9847 & 0.9867 \\
$60 \%$ & 0.9670 & 0.9684 & 0.9587 & 0.9820 & 0.9858 \\
$80 \%$ & 0.9667 & 0.9682 & 0.9552 & 0.9798 & 0.9816 \\
\hline
\end{tabular}

The effects of different noise intensities are also plotted in Figure 5 to show the effects of noise on the five models' overall trends. The general trends showed an association between the increase in noise intensity and a reduction in the determination coefficient's value as expected. High robustness is noticed by the low variance of $R^{2}$ of the triple seasonality of the Holt-Winters model with the least value of 0.9816 at $80 \%$ noise intensity. The Holt-Winters model's single seasonality showed the least robustness among the other models with a minimum value of 0.9552 . The other models showed excellent robustness across the different noise intensities. These results drive to the same previous conclusion that the triple seasonality then double seasonality of the Holt-Winters model outperformed the other models in terms of accuracy, generalization, and robustness.

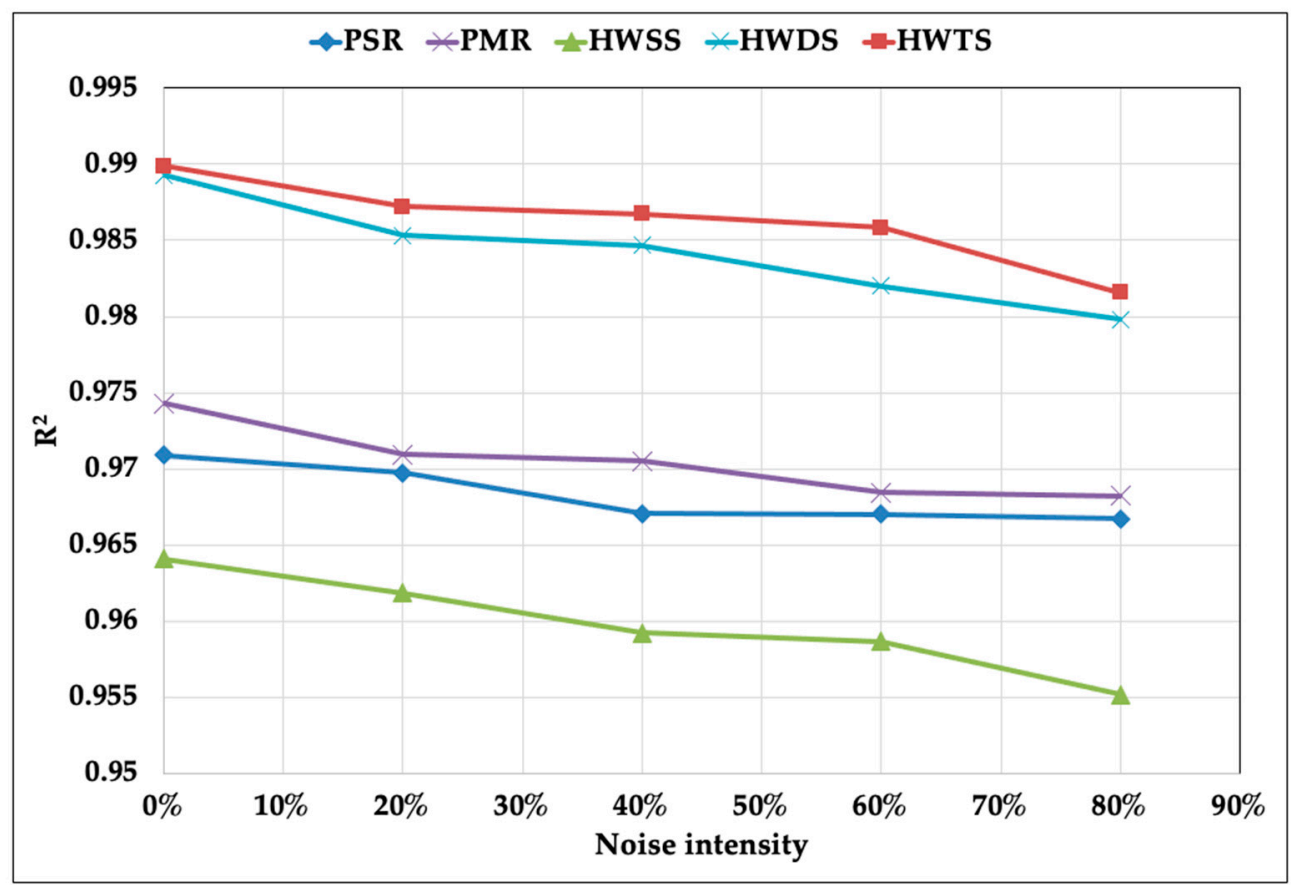

Figure 5. Variations of the coefficient of determination at different noise intensities for the five models. 


\subsection{Future Generation Forecasting}

Long-term electricity forecasting studies can include the peak load forecasting as well as electricity generation forecasting as in the current study [18]. Each of the two forecasting approaches contributes to providing different information for the experts and reveals a comprehensive overview of the electricity grid. One of the common misconceptions is that the generated electricity's annual peak occurs on the same day as the annual peak load. However, this may not be true for all datasets and case studies due to several factors. These factors can be attributed to the nature of the annual peak load date, resulting from the high consumer consumption at a specific time due to temperature, the time during the day, and consumption pattern. The annual peak generation is associated with these factors during the whole day and not at a specific time. As a result, the annual peak load dates are not identical with the annual peak generation dates. Table 5 provides a comparison between the peak load dates, from [18], and the peak generation of this study in Kuwait between 2015-2020. It is evident that forecasting the peak load and the peak generation would be advantageous to policymakers to prepare for the expected loads in terms of logistics needed for the electrical generation. Moreover, it would help in making decisions for expanding the electricity grid and to assess the need for boosting from the current interconnected GCC power grid.

Table 5. The annual peak load and the matching generation and the annual peak generation and date.

\begin{tabular}{cccccc}
\hline Year & Date & Peak Load & $\begin{array}{c}\text { Generation of } \\
\text { the Same Date }\end{array}$ & $\begin{array}{c}\text { Peak } \\
\text { Generation }\end{array}$ & Date \\
\hline 2015 & 30 August 2015 & 12,810 & 279,228 & 279,228 & 30 August 2015 \\
2016 & 15 August 2016 & 13,390 & 288,058 & 290,304 & 2 August 2016 \\
2017 & 26 July 2017 & 13,800 & 290,288 & 299,694 & 14 August 2017 \\
2018 & 10 July 2018 & 13,910 & 284,718 & 300,231 & 12 July 2018 \\
2019 & 27 June 2019 & 14,420 & 318,531 & 318,531 & 27 June 2019 \\
2020 & 30 July 2020 & 14,960 & 317,677 & 326,437 & 31 July 2020 \\
\hline
\end{tabular}

The long-term electric generation forecasting for the year 2020-2030 of the five models, and the actual data are tabulated in Table A1. The forecasted data of the annual electrical generation of the five models are plotted in Figure 6.

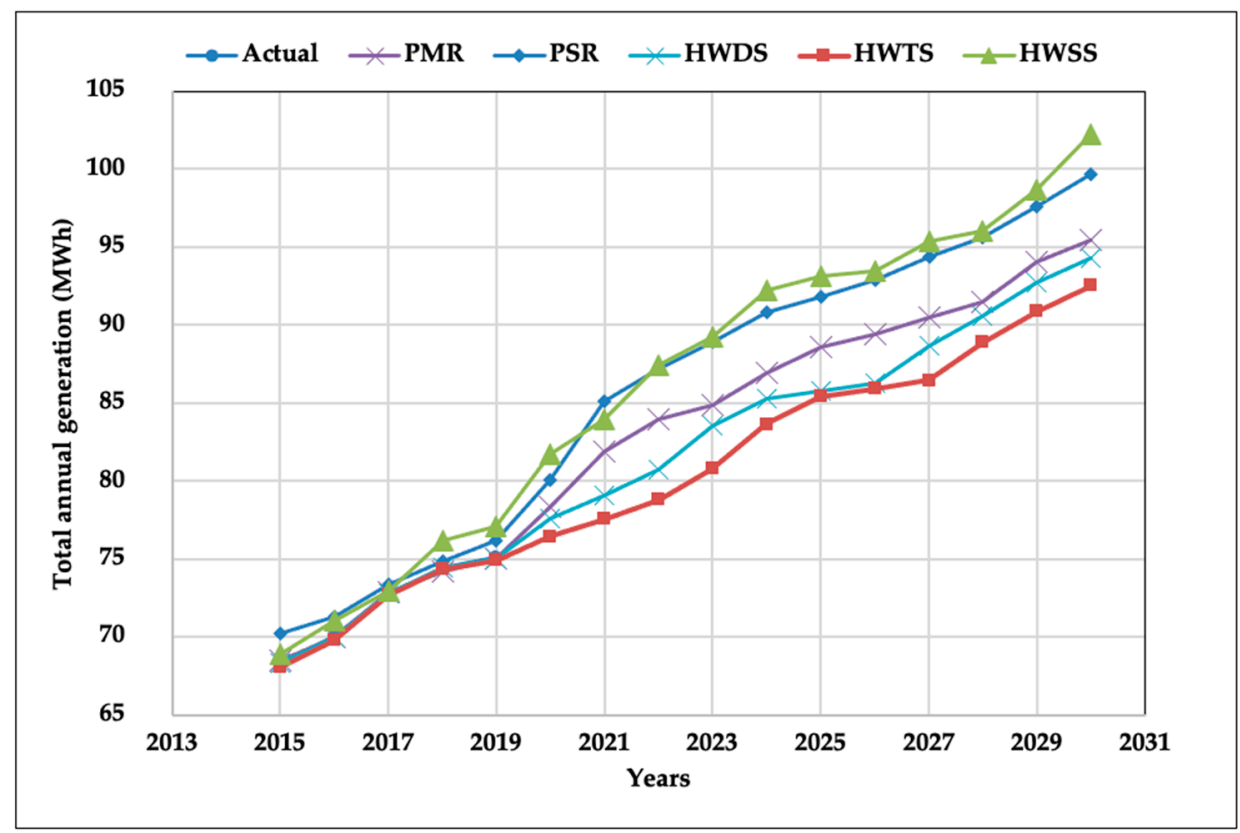

Figure 6. The long-term annual electrical generation forecasting of the five models. 
According to the forecast of the triple seasonality of the Holt-Winters model, the annual electric generation in Kuwait will reach about 92,535,555 kWh by the year 2030. This forecasted value is around $23 \%$ higher than the actual generation in 2019. The other models are higher in the forecasted annual electrical generation, which reaches up to 102,262,507 kWh in single seasonality of Holt-Winters models, which is higher by $36 \%$ than the generation of 2019 . The management needs to assess the needed facility or equipment needed for such a generation to be established and prepared.

The forecasted monthly consumptions of the coming two years for different models are depicted in Table A2 and Figure 7. In addition to the study's primary aim, analyzing the monthly electrical generation can provide mid-term information for the logistics needed for this generation. The highest generation is clearly in two months, July and August, where Kuwait has its harshest weather temperature and humidity. Moreover, the higher electrical generation period of each year is between May and September. The maximum monthly electrical generation in 2021 is July for all the models, whereas August is the maximum in 2022 for the PSR, PMR, and HWSS models, and July 2022 is the maximum for the HWDS and HWTS models. Such information provides management and policymakers with vital tools to reach the right decision for the proper generation of electricity and planning for major maintenance or shutdowns.

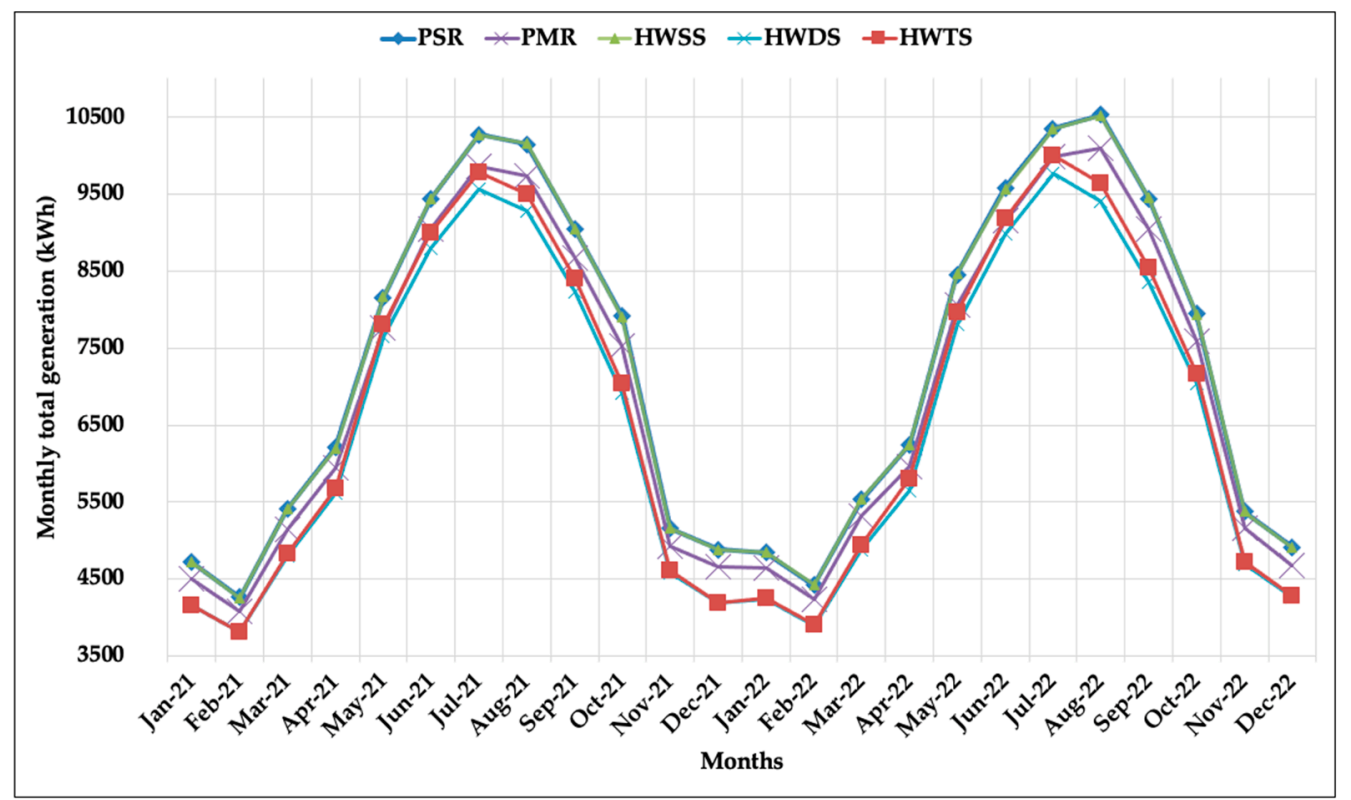

Figure 7. Monthly total generation of electricity for Kuwait between 2021 and 2022.

The monthly electrical generation introduces useful information to determine a map of electrical demand and associated maintenance program. In contrast, the long-term annual electrical generation forecasting help in estimating the fossil fuel power plants' fuel budget. Therefore, addressing fuel costs evaluation constitutes a positive addition in the current research and reflects the primary goal of electrical generation prediction for all-electric power entities.

\subsection{Implications of Elecrical Generation on Fuels Cost}

The long-term annual electrical generation forecasting can be used to estimate the fuel cost of the future till 2030. Since Kuwait is dependent on oil export as the primary source for the country's revenue, the electricity generation directly relates to the country's economy, especially with the depletion of oil due to burning fossil fuel as a fuel in electricity generation. Kuwait's power plants use four different types of fossil fuel: natural gas, gas oil, crude oil, and heavy fuel oil (HFO). The rate of increase in electricity consumption has significant effects on the stability of the country's economy. Therefore, the long-term forecasting of electrical generation is essential for policymakers to keep 
Kuwait's prosperous future. The sharp increase in electrical generation can deplete the oil resources capacity and is critical to Kuwait's economic future. The total cost of fuel consumed in the electrical generation between 2012 and 2019 is tabulated in Table 6 to illustrate the fuel cost change.

Table 6. The consumption of fuels and the total cost of fuel consumption between years 2012-2019 [21-24].

\begin{tabular}{cccccc}
\hline Year & $\begin{array}{c}\text { Natural Gas (KSCF) } \\
\text { Standard Cubic Feet }\end{array}$ & $\begin{array}{c}\text { Gas Oil } \\
\text { (Barrels) }\end{array}$ & $\begin{array}{c}\text { Crude Oil } \\
\text { (Barrels) }\end{array}$ & $\begin{array}{c}\text { Heavy Oil } \\
\text { (Barrels) }\end{array}$ & $\begin{array}{c}\text { Total Cost } \\
\text { (KD) }\end{array}$ \\
\hline $\mathbf{2 0 1 2}$ & $264,080,165$ & $11,913,629$ & $16,566,894$ & $38,557,558$ & $2,423,012,351$ \\
$\mathbf{2 0 1 3}$ & $253,461,108$ & $9,237,306$ & $11,323,855$ & $46,967,101$ & $2,327,992,356$ \\
$\mathbf{2 0 1 4}$ & $313,936,191$ & $11,153,661$ & $14,409,093$ & $37,954,682$ & $2,435,107,934$ \\
$\mathbf{2 0 1 5}$ & $350,979,921$ & $8,570,450$ & $4,849,437$ & $46,722,496$ & $1,288,525,905$ \\
$\mathbf{2 0 1 6}$ & $378,535,102$ & $5,731,758$ & $4,057,944$ & $48,460,342$ & $1,010,903,300$ \\
$\mathbf{2 0 1 7}$ & $374,964,177$ & $5,196,552$ & $9,194,665$ & $41,591,383$ & $1,297,642,956$ \\
$\mathbf{2 0 1 8}$ & $403,438,524$ & $3,623,846$ & $6,236,988$ & $42,956,365$ & $1,694,031,251$ \\
$\mathbf{2 0 1 9}$ & $433,605,520$ & $5,376,675$ & $3,439,839$ & $39,107,701$ & $1,442,738,912$ \\
\hline
\end{tabular}

It is clear from Table 6 that the total cost of fuel is fluctuating and associated with world fuel prices. Assessment of the power and desalination plants' fuel future requirements is vital to secure power generation and water supply stability. However, this may require thorough investigations to address all the parameters and be examined in the future. Instead, the analysis of possible simplified estimation of the total cost of fuel associated with the long-term electrical generation forecasting is introduced to address the uncertainties of fuel prices. The fuel cost represents the first source of expenses based on the life cycle assessment for the whole plant lifespan, which exceeds the capital investment cost. Fossil fuel constitutes about $99.6 \%$ of the total energy supply sources to the Kuwait power sector [21-24], and the high percentage level of dependency is typical in most oil countries.

There are two natural gas sources in Kuwait, local and imported liquefied natural gas (LNG). However, each type of fossil fuel has its own chemical and physical characteristics, and the price fluctuates according to several factors such as source, quality of the fuel, and demand-supply bases. The percentage of fuel consumptions map are varied year per year in power generation sectors and mainly governed by the strategies of Kuwait Petroleum Corporation (KPC), which is oriented economically. The fixed baseline of fuel price was selected throughout this work, as illustrated in Table 7 , based on the average values extracted from the past five years data to evaluate the fuel budget for the next ten years using the five models' extracted outcomes.

Table 7. Average prices of the different fossil fuels used in power generation in Kuwait.

\begin{tabular}{ccccc}
\hline \multirow{2}{*}{ Fuel } & \multicolumn{3}{c}{ Price } & \multirow{2}{*}{ Unit } \\
\cline { 2 - 4 } & Low & Average & High & \\
\hline Natural Gas & 0.294 & 0.375 & 0.456 & KD/MSCF \\
Gas Oil & 11.846 & 18.904 & 25.963 & $\mathrm{KD} / \mathrm{bbl}$ \\
Crude Oil & 8.084 & 14.085 & 20.085 & $\mathrm{KD} / \mathrm{bbl}$ \\
H.F.O. & 6.496 & 13.398 & 20.300 & $\mathrm{KD} / \mathrm{bbl}$ \\
LNG & 1.265 & 2.626 & 3.987 & $\mathrm{KD} / \mathrm{MSCF}$ \\
\hline
\end{tabular}

Single and triple seasonality Holt-Winters models are the two models that cover the upper and lower band of the estimated cost of the forecasted annual electricity generation for Kuwait from 2020-2030 as it can be observed in Figure 8. Estimating the fuel budget is not limited only to the economic criteria but also to technical factors, such as type of unit, heat rate, degradation, and fuel quality. For the sake of simplicity, the average degradation value for the unit heat rate was assumed $1 \%$ as per registered and proposed by the manufacturers at standard conditions. Figure 8 shows the 
forecasted fuel budget for the Kuwait power and desalination plants in millions of Kuwaiti Dinars up to 2030 using all proposed models.

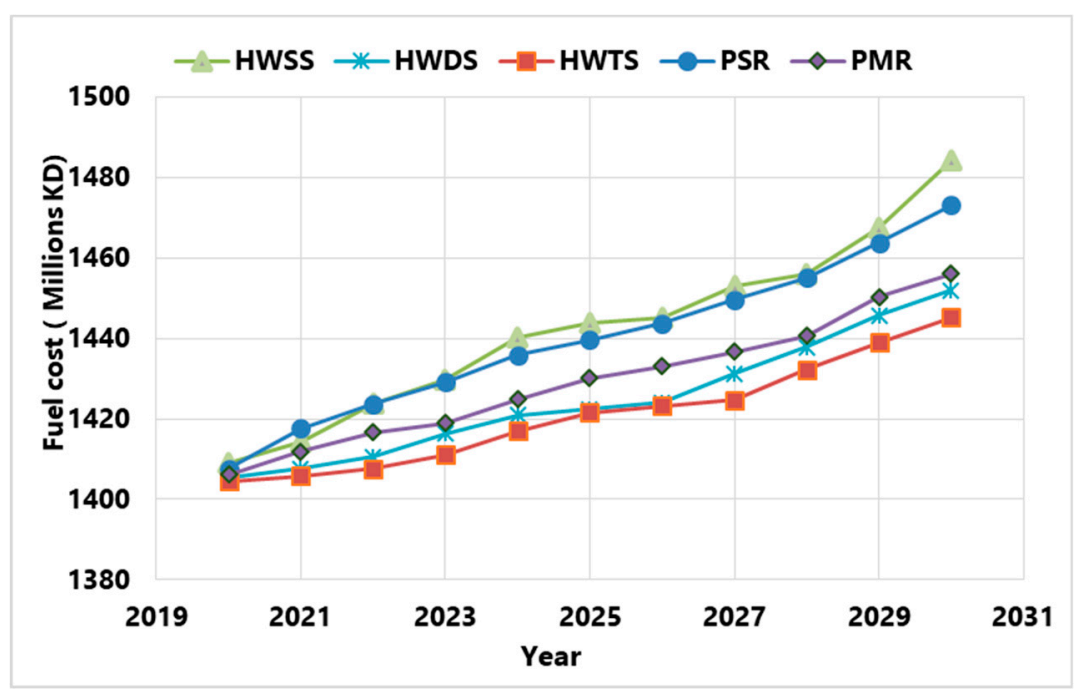

Figure 8. Forecasted fuel budget in millions of Kuwaiti Dinars for the upcoming ten years based on the power generation prediction of all proposed models.

All models elucidate consistent trend through the gradual increase in fuel cost due to increasing power generation. The gap between the upper model (HWSS) and lower model (HWTS) outcomes, as it can be noticed in Figure 8, increases at the end of the tested period compared to the beginning because of the rise in expected power generation difference, which exceeds 9 million $\mathrm{kWh}$ total annual production. The moderate growth of the fuel budget might be attributed to the rising dependency on natural gas on other liquid fossil fuels. Relying more on natural gas as a significant fuel source is evident in the electricity value between them.

The primary contribution of fuel to the total fossil fuel budget comes from natural gas with LNG, followed by Heavy fuel oil, gas oil, and crude oil for the year 2020, while gas oil and crude oil have the same contribution by $5 \%$ in the year 2030 as illustrated in Figure 9.

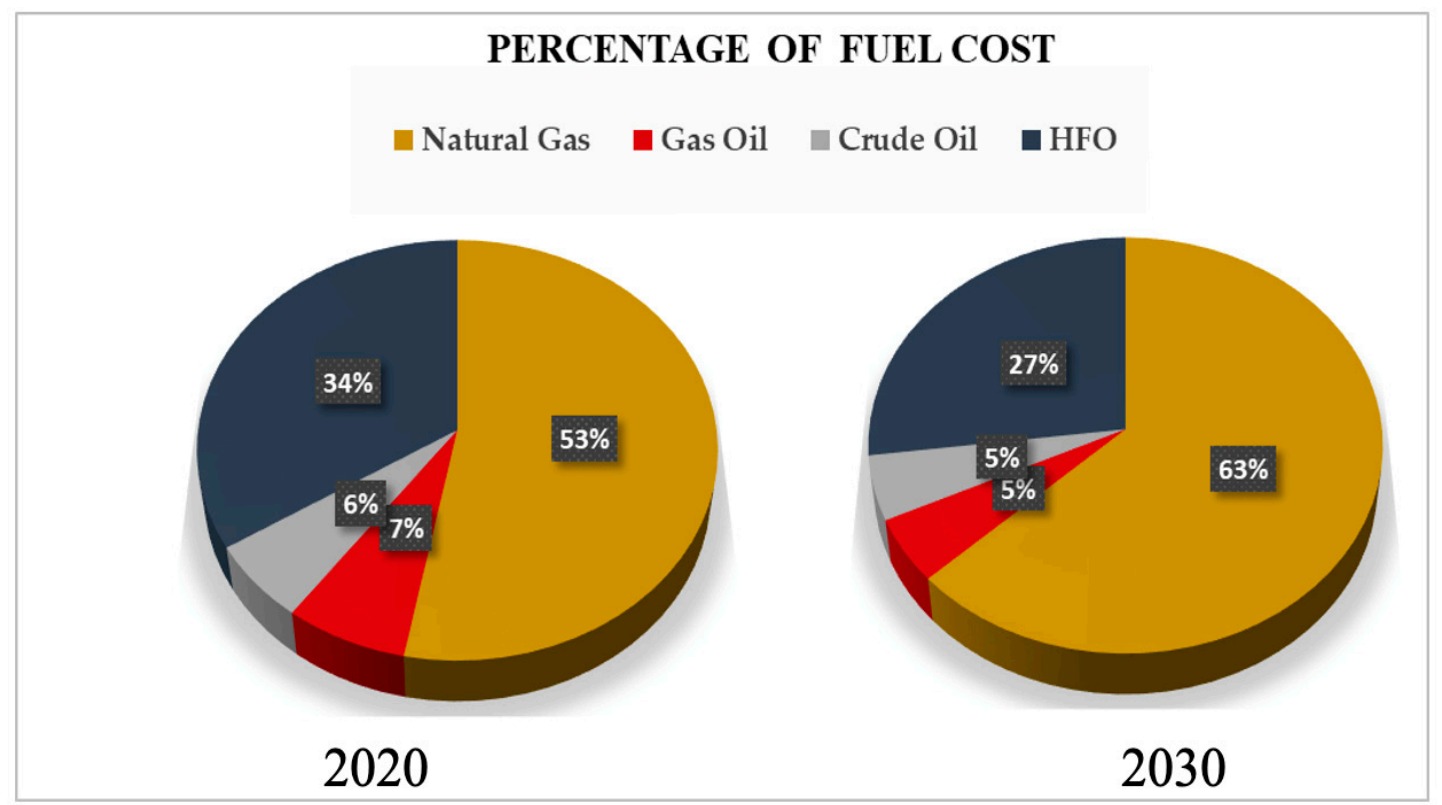

Figure 9. Fuel contribution cost as a percentage of total fossil fuel cost for the years 2020 and 2030. 
The fuel distribution estimation was determined based on the actual fuel scenarios over the last five years, which do not depend on fuel price only but govern by fuel availability and type of available units. The distribution pattern shows that the natural gas share increases over the examined period by $10.9 \%$, whereas the liquid fossil fuel reduces by $8.1 \%$. The present study has confirmed the advantage of securing more natural gas on fuel future map by cost-effectively selecting new energy systems. The MEW's future fuel budget can be reduced by securing more local natural gas and implementing large-capacity renewable energy projects.

\section{Conclusions}

Long-term forecasting of electrical generation in Kuwait was investigated using five models to predict the electrical generation until 2030. Different statistical performance metrics were employed to assess the accuracy, generalization, and robustness of the models. The Holt-Winters model's triple seasonality outperformed the other models in terms of the MAPE, RMSE, CVRMSE, MAE, and ${ }^{2}$. According to the different performance indicators, the double seasonality of the Holt-Winters model was the second-best performing model with superior accuracy. The Prophet model, with multiple regressors, has shown comparable performance to the Holt-Winters double seasonality model. In contrast, the least performing models were the single regressor Prophet model followed by the single seasonality Holt-Winters model. The estimated annual electrical generation for the year 2030 of the Holt-Winters models' triple and single seasonality models were 92,535,555 and 102,262,507 kWh, respectively. The generation of electricity in Kuwait during the upcoming ten years was then presented and discussed. The results reveal that the higher electrical generation period occurs between May and September of the upcoming two years. The five models' long-term electrical generation forecast was then used to estimate the fuel's total cost to provide an overview for policymakers to support the execution of planning decisions.

Author Contributions: Conceptualization, A.I.A., A.M.A., and A.S.A.; methodology, A.M.A. and A.I.A.; software, A.M.A.; validation, A.M.A., A.I.A., A.S.A., M.R.A., and S.N.A.; formal analysis, A.M.A., A.I.A., A.S.A., and F.M.A.; investigation, A.M.A., A.I.A., and A.S.A.; resources, A.M.A., A.I.A., A.S.A., M.R.A., S.N.A., and F.M.A.; data curation, A.I.A., A.M.A., A.S.A., and F.M.A.; writing-original draft preparation, A.I.A., A.M.A., and A.S.A.; writing-review and editing, A.I.A., A.M.A., A.S.A., M.R.A., and S.N.A.; visualization, A.I.A., A.M.A., and A.S.A. All authors have read and agreed to the published version of the manuscript.

Funding: This research received no external funding.

Conflicts of Interest: The authors declare no conflict of interest.

\section{Nomenclature}

$\begin{array}{ll}\text { GDP } & \text { Gross domestic product } \\ \text { AI } & \text { Artificial intelligence } \\ \text { ML } & \text { Machine learning } \\ \text { DL } & \text { Deep learning } \\ \text { GA } & \text { Genetic algorithm } \\ \text { ANN } & \text { Artificial neural networks } \\ \text { SVR } & \text { Support vector regression } \\ \text { IPSO } & \text { Improved particle swarm optimization } \\ \text { PCA-FFNN } & \text { Principal component analysis and fuzzy feed-forward neural network } \\ \text { PCFI-RBF } & \text { Partial-consensus fuzzy intersection and radial basis function network } \\ \text { RMSE } & \text { Root mean square error } \\ \text { MAPE } & \text { Mean absolute percentage error } \\ \text { R } & \text { Coefficient of determination } \\ \text { MAE } & \text { Mean absolute error } \\ \text { CVRMSE } & \text { Coefficient of variation of root mean square error } \\ \text { PSR } & \text { Single regressor for Prophet Model } \\ \text { PMR } & \text { Multiple regressors for Prophet Model } \\ \text { HWSS } & \text { Single seasonality Holt-Winters model }\end{array}$


HWDS Double seasonality Holt-Winters model

HWTS Triple seasonality Holt-Winters model

HFO Heavy fuel oil

LNG Liquefied natural gas

KPC Kuwait Petroleum Corporation

\section{Appendix A}

Table A1. The real data and the forecasted annual generation of electricity for Kuwait from 2015-2030.

\begin{tabular}{ccccccc}
\hline \multicolumn{7}{c}{ Annual Total Electrical Generation (kWh) } \\
\cline { 2 - 7 } & Actual & PSR & PMR & HWSS & HWDS & HWTS \\
\hline 2015 & $68,286,350$ & $70,208,828$ & $68,449,290$ & $68,935,381$ & $68,299,370$ & $68,047,664$ \\
2016 & $70,084,727$ & $71,309,681$ & $69,977,535$ & $71,082,353$ & $70,008,887$ & $69,798,293$ \\
2017 & $72,787,590$ & $73,359,898$ & $72,903,860$ & $72,910,975$ & $72,810,502$ & $72,665,778$ \\
2018 & $74,430,304$ & $74,872,001$ & $74,156,996$ & $76,173,631$ & $74,432,331$ & $74,326,541$ \\
2019 & $75,069,410$ & $76,179,317$ & $75,040,336$ & $77,113,949$ & $75,008,034$ & $74,916,365$ \\
2020 & & $80,036,707$ & $78,329,573$ & $81,683,193$ & $77,607,284$ & $76,441,652$ \\
2021 & & $85,131,998$ & $81,893,161$ & $83,971,685$ & $79,070,098$ & $77,576,721$ \\
2022 & & $87,184,615$ & $83,945,450$ & $87,453,223$ & $80,757,167$ & $78,803,803$ \\
2023 & & $88,888,944$ & $84,818,623$ & $89,208,193$ & $83,518,864$ & $80,801,914$ \\
2024 & & $90,819,983$ & $86,916,798$ & $92,262,607$ & $85,265,977$ & $83,624,082$ \\
2025 & & $91,833,231$ & $88,556,264$ & $93,165,837$ & $85,770,309$ & $85,417,389$ \\
2026 & & $92,878,920$ & $89,406,883$ & $93,465,256$ & $86,293,807$ & $85,933,949$ \\
2027 & $94,350,541$ & $90,451,648$ & $95,353,865$ & $88,667,276$ & $86,469,671$ \\
2028 & & $95,636,495$ & $91,515,320$ & $96,037,295$ & $90,582,478$ & $88,899,766$ \\
2029 & & $97,623,149$ & $94,049,623$ & $98,668,062$ & $92,751,443$ & $90,860,715$ \\
2030 & & $99,677,375$ & $95,421,752$ & $102,262,507$ & $94,313,533$ & $92,535,555$ \\
\hline
\end{tabular}

Table A2. The forecasted monthly generation of electricity for Kuwait between 2021 and 2022.

\begin{tabular}{cccccc}
\hline & \multicolumn{5}{c}{ Monthly Total Generation (kWh) } \\
\cline { 2 - 6 } & PSR & PMR & HWSS & HWDS & HWTS \\
\hline 21 January & $4,719,195$ & $4,506,418$ & $4,723,899$ & $4,154,973$ & $4,160,775$ \\
21 February & $4,265,083$ & $4,085,284$ & $4,253,269$ & $3,812,010$ & $3,819,632$ \\
21 March & $5,407,054$ & $5,148,962$ & $5,413,977$ & $4,797,070$ & $4,828,850$ \\
21 April & $6,207,547$ & $5,940,924$ & $6,196,026$ & $5,609,673$ & $5,679,516$ \\
21 May & $8,150,344$ & $7,765,217$ & $8,169,369$ & $7,655,697$ & $7,802,910$ \\
21 June & $9,445,881$ & $9,051,420$ & $9,446,366$ & $8,798,820$ & $8,997,350$ \\
21 July & $10,276,964$ & $9,856,725$ & $10,275,340$ & $9,567,496$ & $9,791,745$ \\
21 August & $10,152,294$ & $9,738,065$ & $10,157,051$ & $9,287,612$ & $9,500,731$ \\
21 September & $9,048,569$ & $8,676,132$ & $9,050,778$ & $8,229,272$ & $8,404,845$ \\
21 October & $7,912,560$ & $7,534,398$ & $7,904,534$ & $6,922,840$ & $7,040,503$ \\
21 November & $5,160,468$ & $4,926,339$ & $5,163,376$ & $4,584,972$ & $4,613,376$ \\
21 December & $4,884,369$ & $4,663,277$ & $4,878,559$ & $4,186,849$ & $4,194,054$ \\
22 January & $4,841,008$ & $4,639,763$ & $4,849,182$ & $4,240,582$ & $4,251,986$ \\
22 February & $4,423,749$ & $4,236,537$ & $4,423,660$ & $3,890,423$ & $3,903,769$ \\
22 March & $5,532,091$ & $5,310,500$ & $5,534,806$ & $4,884,470$ & $4,934,148$ \\
22 April & $6,248,921$ & $5,960,376$ & $6,239,217$ & $5,639,118$ & $5,802,449$ \\
22 May & $8,455,250$ & $8,067,020$ & $8,473,173$ & $7,812,368$ & $7,970,160$ \\
22 June & $9,582,494$ & $9,164,224$ & $9,567,936$ & $8,978,583$ & $9,189,225$ \\
22 July & $10,355,563$ & $9,995,653$ & $10,348,046$ & $9,762,630$ & $10,000,339$ \\
22 August & $10,534,098$ & $10,092,835$ & $10,528,398$ & $9,414,655$ & $9,637,299$ \\
22 September & $9,431,675$ & $9,043,116$ & $9,461,242$ & $8,355,913$ & $8,540,640$ \\
22 October & $7,942,639$ & $7,593,484$ & $7,936,245$ & $7,039,516$ & $7,165,731$ \\
22 November & $5,376,527$ & $5,160,420$ & $5,371,959$ & $4,683,238$ & $4,718,244$ \\
22 December & $4,912,699$ & $4,681,523$ & $4,909,340$ & $4,271,941$ & $4,285,130$ \\
\hline
\end{tabular}




\section{References}

1. Weron, R. Modeling and Forecasting Electricity Loads and Prices: A Statistical Approach; John Wiley \& Sons: Chicester, UK, 2007; Volume 403.

2. Wei, N.; Li, C.; Peng, X.; Zeng, F.; Lu, X. Conventional models and artificial intelligence-based models for energy consumption forecasting: A review. J. Pet. Sci. Eng. 2019, 181, 106187. [CrossRef]

3. Lindberg, K.B.; Seljom, P.; Madsen, H.; Fischer, D.; Korpås, M. Long-term electricity load forecasting: Current and future trends. Util. Policy 2019, 58, 102-119. [CrossRef]

4. Kuster, C.; Rezgui, Y.; Mourshed, M. Electrical load forecasting models: A critical systematic review. Sustain. Cities Soc. 2017, 35, 257-270. [CrossRef]

5. Scheidt, F.v.; Medinová, H.; Ludwig, N.; Richter, B.; Staudt, P.; Weinhardt, C. Data analytics in the electricity sector-A quantitative and qualitative literature review. Energy AI 2020, 1, 100009. [CrossRef]

6. Amasyali, K.; El-Gohary, N.M. A review of data-driven building energy consumption prediction studies. Renew. Sustain. Energy Rev. 2018, 81, 1192-1205. [CrossRef]

7. Khuntia, S.R.; Rueda, J.L.; van der Meijden, M.A. Forecasting the load of electrical power systems in mid-and long-term horizons: A review. IET Gener. Transm. Distrib. 2016, 10, 3971-3977. [CrossRef]

8. Alfares, H.K.; Nazeeruddin, M. Electric load forecasting: Literature survey and classification of methods. Int. J. Syst. Sci. 2002, 33, 23-34. [CrossRef]

9. Pérez-García, J.; Moral-Carcedo, J. Analysis and long term forecasting of electricity demand trough a decomposition model: A case study for Spain. Energy 2016, 97, 127-143. [CrossRef]

10. Torrini, F.C.; Souza, R.C.; Cyrino Oliveira, F.L.; Moreira Pessanha, J.F. Long term electricity consumption forecast in Brazil: A fuzzy logic approach. Socio-Econ. Plan. Sci. 2016, 54, 18-27. [CrossRef]

11. Pessanha, J.F.M.; Leon, N. Forecasting Long-term Electricity Demand in the Residential Sector. Procedia Comput. Sci. 2015, 55, 529-538. [CrossRef]

12. Mohamed, Z.; Bodger, P. Forecasting electricity consumption in New Zealand using economic and demographic variables. Energy 2005, 30, 1833-1843. [CrossRef]

13. Ardakani, F.J.; Ardehali, M.M. Long-term electrical energy consumption forecasting for developing and developed economies based on different optimized models and historical data types. Energy 2014, 65, 452-461. [CrossRef]

14. Bianco, V.; Manca, O.; Nardini, S. Electricity consumption forecasting in Italy using linear regression models. Energy 2009, 34, 1413-1421. [CrossRef]

15. Chen, T.; Wang, Y.-C. Long-term load forecasting by a collaborative fuzzy-neural approach. Int. J. Electr. Power Energy Syst. 2012, 43, 454-464. [CrossRef]

16. da Silva, F.L.C.; Cyrino Oliveira, F.L.; Souza, R.C. A bottom-up bayesian extension for long term electricity consumption forecasting. Energy 2019, 167, 198-210. [CrossRef]

17. Taylor, S.J.; Letham, B. Forecasting at Scale. Am. Stat. 2018, 72, 37-45. [CrossRef]

18. Almazrouee, A.I.; Almeshal, A.M.; Almutairi, A.S.; Alenezi, M.R.; Alhajeri, S.N. Long-Term Forecasting of Electrical Loads in Kuwait Using Prophet and Holt-Winters Models. Appl. Sci. 2020, 10, 5627. [CrossRef]

19. Trull, O.; García-Díaz, J.C.; Troncoso, A. Initialization Methods for Multiple Seasonal Holt-Winters Forecasting Models. Mathematics 2020, 8, 268. [CrossRef]

20. Jiang, W.; Wu, X.; Gong, Y.; Yu, W.; Zhong, X. Holt-Winters smoothing enhanced by fruit fly optimization algorithm to forecast monthly electricity consumption. Energy 2020, 193, 116779. [CrossRef]

21. MEW. Statistical Year Book, State of Kuwait Ministry of Electricity and Water; MEW: Kuwait City, Kuwait, 2020.

22. MEW. Statistical Year Book, State of Kuwait Ministry of Electricity and Water; MEW: Kuwait City, Kuwait, 2019.

23. MEW. Statistical Year Book, State of Kuwait Ministry of Electricity and Water; MEW: Kuwait City, Kuwait, 2018.

24. MEW. Statistical Year Book, State of Kuwait Ministry of Electricity and Water; MEW: Kuwait City, Kuwait, 2017.

25. Ali, H.; Alsabbagh, M. Residential Electricity Consumption in the State of Kuwait. Envrion. Pollut Clim. Chang. 2018, 2. [CrossRef]

26. Soares, N.; Reinhart, C.F.; Hajiah, A. Simulation-based analysis of the use of PCM-wallboards to reduce cooling energy demand and peak-loads in low-rise residential heavyweight buildings in Kuwait. Build. Simul. 2017, 10, 481-495. [CrossRef]

27. Matar, W.; Anwer, M. Jointly reforming the prices of industrial fuels and residential electricity in Saudi Arabia. Energy Policy 2017, 109, 747-756. [CrossRef] 
28. Shehabi, M. Assessing Kuwaiti Energy Pricing Reforms; Oxford Institute for Energy Studies: Oxford, UK, 2017.

29. Santosa, B. Dynamic Pricing in Electricity: Research Potential in Indonesia. Procedia Manuf. 2015, 4, 300-306.

30. Alajmi, A. Energy audit of an educational building in a hot summer climate. Energy Build. 2012, 47, 122-130. [CrossRef]

31. Gaete-Morales, C.; Gallego-Schmid, A.; Stamford, L.; Azapagic, A. A novel framework for development and optimisation of future electricity scenarios with high penetration of renewables and storage. Appl. Energy 2019, 250, 1657-1672. [CrossRef]

32. Alajmi, T.; Phelan, P. Modeling and Forecasting End-Use Energy Consumption for Residential Buildings in Kuwait Using a Bottom-Up Approach. Energies 2020, 13, 1981. [CrossRef]

33. AlHajri, M.; AlRashidi, M.; EL-Naggar, K. Long-term electric load forecast in Kuwaiti and Egyptian power systems. J. Eng. Res. 2018, 6, 116-135.

34. Almeshaiei, E.; Soltan, H. A methodology for Electric Power Load Forecasting. Alex. Eng. J. 2011, 50, $137-144$. [CrossRef]

35. Alhajeri, H.M.; Almutairi, A.; Alenezi, A.; Alshammari, F. Energy Demand in the State of Kuwait During the Covid-19 Pandemic: Technical, Economic, and Environmental Perspectives. Energies 2020, 13, 4370. [CrossRef]

36. AlRashidi, M.R.; El-Naggar, K.M. Long term electric load forecasting based on particle swarm optimization. Appl. Energy 2010, 87, 320-326. [CrossRef]

37. Atalla, T.N.; Hunt, L.C. Modelling residential electricity demand in the GCC countries. Energy Econ. 2016, 59, 149-158. [CrossRef]

38. Bianchi, F.; Castellini, A.; Tarocco, P.; Farinelli, A. Load Forecasting in District Heating Networks: Model Comparison on a Real-World Case Study. In Proceedings of the International Conference on Machine Learning, Optimization, and Data Science, Siena, Italy, 10-13 September 2019; Springer: Cham, Switzerland, 2019; pp. 553-565.

39. Rehman, S.A.U.; Cai, Y.; Fazal, R.; Das Walasai, G.; Mirjat, N.H. An integrated modeling approach for forecasting long-term energy demand in Pakistan. Energies 2017, 10, 1868. [CrossRef]

40. Hussain, A.; Rahman, M.; Memon, J.A. Forecasting electricity consumption in Pakistan: The way forward. Energy Policy 2016, 90, 73-80. [CrossRef]

41. García-Díaz, J.C.; Trull, Ó. Competitive Models for the Spanish Short-Term Electricity Demand Forecasting. In Time Series Analysis and Forecasting; Springer: Cham, Switzerland, 2016; pp. 217-231.

42. Brockwell, P.J.; Davis, R.A.; Calder, M.V. Introduction to Time Series and Forecasting; Springer: Cham, Switzerland, 2002; Volume 2.

43. Trull, Ó.; García-Díaz, J.C.; Troncoso, A. Stability of Multiple Seasonal Holt-Winters Models Applied to Hourly Electricity Demand in Spain. Appl. Sci. 2020, 10, 2630. [CrossRef]

44. Lewis, C.D. Industrial and Business Forecasting Methods: A Practical Guide to Exponential Smoothing and Curve Fitting; Butterworth-Heinemann: London, UK, 1982.

45. Wang, R.; Lu, S.; Feng, W. A novel improved model for building energy consumption prediction based on model integration. Appl. Energy 2020, 262, 114561. [CrossRef]

46. Cai, M.; Pipattanasomporn, M.; Rahman, S. Day-ahead building-level load forecasts using deep learning vs. traditional time-series techniques. Appl. Energy 2019, 236, 1078-1088. [CrossRef]

Publisher's Note: MDPI stays neutral with regard to jurisdictional claims in published maps and institutional affiliations.

(C) 2020 by the authors. Licensee MDPI, Basel, Switzerland. This article is an open access article distributed under the terms and conditions of the Creative Commons Attribution (CC BY) license (http://creativecommons.org/licenses/by/4.0/). 